\title{
PENGARUH FIRM SIZE, LIKUIDITAS, STRUKTUR MODAL TERHADAP PROFITABILITAS
}

\author{
Oleh : Ferlina Ekinanda \\ ferlinaekinanda01@gmail.com \\ (Program Studi Akuntansi, FE Universitas Islam Batik Surakarta)
}

\begin{abstract}
Abstrak-Penelitian ini mempunyai tujuan untuk menguji pengaruh firm size, likuiditas dan struktur modal terhadap profitabilitas. Metode penelitian yang digunakan adalah deskriptif kuantitatif. Jenis data yang digunakan dalam penelitian ini berupa data sekunder berupa laporan tahunan perusahaan makanan dan minuman pada Bursa Efek Indonesia pada tahun 2016-2018. Jumlah sampel yang digunakan sebanyak 12 perusahaan sektor makanan dan minuman yang terdaftar di Bursa Efek Indonesia pada tahun 2016-2018. Teknik analisis data yang digunakan dalam penelitian ini adalah uji asumsi klasik dan regresi linear berganda. Hasil penelitian menunjukan bahwa variabel firm size tidak berpengaruh terhadap profitabilitas. Sementara likuiditas dan struktur modal berpengaruh terhadap profitabilitas sebesar 15,1\%. Dan 84,9\% dipengaruhi oleh faktor lain yang tidak diteliti dalam penelitian ini.
\end{abstract}

Kata Kunci: Profitabilitas, Firm Size, Likuiditas, Struktur Modal.

\begin{abstract}
This study aims to examine the effect of firm size, liquidity and capital structure on profitability. The research method used is descriptive quantitative. The type of data used in this study is secondary data in the form of annual reports of food and beverage companies on the Indonesia Stock Exchange in 2016-2018. The number of samples used was 12 food and beverage sector companies listed on the Indonesia Stock Exchange in 2016-2018. Data analysis techniques used in this study are the classic assumption test and multiple linear regression. The results showed that the firm size variable did not affect profitability. While liquidity and capital structure affect the profitability of $15.1 \%$. And $84.9 \%$ is influenced by other factors not examined in this stud.
\end{abstract}

Keywords: Profitability, Firm Size, Liquidity, Capital Structure.

\section{PENDAHULUAN}

Dalam menghadapi persaingan global, Perusahaan dituntut untuk dapat mengantisipasi persaingan yang terjadi pada perusahaaan. Dengan adanya persaingan antar perusahaan khususnya perusahaan sektor makanan dan minuman melakukan kegiatan ekonomi dan fungsi yang terkait didalam perusahaan secara efektif. Salah satu upaya yang dilakukan oleh perusahaan untuk mengukur hasil usaha dan perkembangan perusahaan dari waktu ke waktu yaitu dengan menyusun laporan keuangan. Laporan keuangan merupakan alat yang sangat penting untuk manajer 
perusahaan karena dengan itu manajer dapat memperoleh informasi yang berhubungan dengan posisi keuangan yang telah dicapai oleh perusahaan tersebut.

Ukuran dari suatu perusahaan sangat penting di dunia saat ini karena perusahaan besar dapat memproduksi item pada banyak biaya yang lebih rendah berbeda dengan perusahaan-perusahaan kecil. Jadi, ukuran perusahaan telah menjadi sebagai variabel populer dalam menjelaskan profitabilitas organisasi dan sejumlah studi telah meneliti pengaruh ukuran perusahaan terhadap profitabilitas (Niresh et al, 2014;. Wu, 2006;. Athanasoglou et al, 2008; Punnose, 2008).
Likuiditas

menunjukkan

perusahaan untuk kewajiban atas keuangan yang harus di bayar saat ditagih, sedangkan untuk profitabilitas sendiri mengukur kemampuan perusahaan dalam menciptakan keuntungan baik laba maupun modal.

Sumber daya utamanya adalah modal sendiri yang diinvestasikan dalam aset perusahaan, seperti aset lancar, aset tetap, dan aset lainnya (Pontoh dan Ilat, 2013).

Profitabilitas perusahaan merupakan kemampuan dalam menghasilkan laba dari aktivitas yang dilakukan pada periode tertentu. Laba menjadi indikator bagi para stakeholder untuk menilai sampai sejauh mana kinerja manajemen dalam mengolah perusahaan. Kemampuan perusahaan dalam memperoleh laba dapat diukur dari cara menganalisa laporan keuangan melalui rasio profitabilitas. Sumaila (2015) berpendapat bahwa jika holding likuiditas menjadi masalah peraturan, mungkin datang dengan beberapa biaya untuk bank yang dapat mempengaruhi profitabilitas mereka. Pengukuran profitabilitas dilakukan dengan menggunakan berbagai alat ukur dengan kinerjanya yang berbedabeda antara satu penelitian dengan penelitian lainnya (Hafsah dan Sari, 2015).

Penelitian yang dilakukan Purba dan Yadnya (2015) menemukan bahwa profitabilitas dipengaruhi secara positif signifikan oleh ukuran perusahaan. Tujuan dari didirikannya perusahaan adalah untuk memperoleh keuntungan dan mempertahankan eksistensi perusahaan, dengan cara meningkatkan seluruh aktivitas perusahaan dan mengoptimalkan sumber daya yang dimiliki agar perusahaan mencapai laba yang maksimal (Dwiyanthi dan Sudiartha, 2017). Menurut Novita dan Sofie (2015) ada dua variabel yang mempengaruhi profitabilitas, yaitu struktur modal dan likuiditas. Dari penelitian ini struktur modal dan likuiditas berpengaruh signifikan terhadap profitabilitas.

Maka dari itu, penelitian ini dimaksudkan adanya perbedaan 
faktor yang mempengaruhi profitabilitas. Dalam variabel independen tersebut faktor yang mempengaruhi profitabilitas pada perusahaan makanan dan minuman di BEI tahun 2016-2018. Faktor pertama yang dipilih yaitu Firm size karena Firm Size merupakan salah satu tolak ukur perusahaan untuk memastikan seberapa besar dapat menguasai pangsa pasar dan memperoleh keuntungan yang dihitung berdasarkan total aset yang dimiliki. Faktor kedua yaitu Likuiditas karena likuiditas mempunyai hubungan erat dengan profitabilitas, likuiditas menunjukkan tingkat ketersediaan modal yang dibutuhkan untuk menjalankan kegiatan operasional suatu perusahaan. Faktor ketiga yaitu Struktur modal merupakan salah satu komponen yang sangat penting sebagai landasan pengambilan keputusan pembelanjaan bagi suatu perusahaan. Dalam menentukan struktur modal, perusahaan harus mempertimbangkan sifat dan biaya dari masing-masing sumber dana yang dipilih, karena setiap sumber dana mempunyai konsekuensi finansial yang berbeda.

Perusahaan dalam penelitian ini yang akan diteliti yaitu perusahaan makanan dan minuman. Alasan diambilnya sektor makanan dan minuman dalam penelitian ini merupakan kontribusi terbesar dalam sektor ekonomi. Sektor ini memiliki daya saing yang tinggi karena didukung dengan sumber daya alam yang cukup potensial sehingga mampu meningkat Profitabilitas suatu perusahaan sektor makanan dan minuman.

Dari uraian latar belakang diatas maka penelitian ini mengambil judul "Pengaruh Firm Size, Likuiditas, Struktur Modal Terhadap Profitabilitas Pada Perusahaan Sektor makanan dan minuman yang terdaftar di BEI tahun 2016-2018".

\section{METODE PENELITIAN}

Variabel independen adalah variabel yang menjadi sebab perubahan timbulnya variabel dependen, maka dalam penelitian ini yang menjadi variabel bebas dalam penelitian ini yaitu "Firm Size, Likuiditas dan Struktur Modal”.

Penelitian ini merupakan jenis penelitian deskriptif kuantitatif yaitu penelitian yang variabelnya diukur dengan menggunakan simbol angka yang berbeda-beda sesuai dengan kategori informasi yang berkaitan dengan variabel. Sampel dalam penelitian ini menggunakan metode purposive sampling yaitu sampel ditentukan sesuai dengan kriteria tertentu. Dalam penelitian ini menggunakan 12 Perusahaan Makanan dan Minuman dengan Metode yang digunakan penelitian ini yaitu metode purposive sampling Tujuan dari penelitian ini adalah melihat pengaruh variabel terhadap variabel lainnya. Jenis data yang 
digunakan dalam penelitian ini adalah data sekunder yaitu data kuantitatif yang diperoleh dari www.idx.co.id berupa data laporan keuangan perusahaan makanan dan minuman yang terdaftar di BEI pada periode tahun 2016-2018.

1. Profitabilitas

Profitabilitas yaitu pendapatan perusahaan yang sudah dikurangi biaya-biaya.

Profitabilitas

$$
=\underline{\text { Laba Bersih Setelah Pajak }}
$$

Total Aktiva

\section{Firm Size}

Tingkat besar atau kecilnya suatu perubahan yang dapat didasarkan pada total aktiva, penjualan, atau ekuitas.

Firm Size $=$ Logarithm natural (Ln) of Total Assets

3. Likuiditas

Kemampuan perusahaan untuk menjual sebuah aset guna mendapatkan kas pada waktu yang singkat.

Current Ratio

$$
=\frac{\text { Aset Lancar }}{\text { Hutang Lancar }}
$$

\section{Struktur Modal}

Pembiayaan perusahaan yang bersifat permanen yang terdiri dari hutang jangka panjang, saham biasa dan saham preferen.

Struktur Modal

$$
=\frac{\text { Total Hutang }}{\text { Total Aktiva }}
$$

\section{HASIL DAN PEMBAHASAN}

\section{Uji Statistik Deskriptif}

Analisis statistik deskriptif untuk melihat gambaran secara umum dari data yang telah didapatkan. Pada penelitian ini pengukurannya memusatkan pada

\begin{tabular}{|c|c|c|c|c|c|}
\hline & $\mathrm{N}$ & $\begin{array}{l}\text { Minimu } \\
\text { mi }\end{array}$ & $\begin{array}{l}\text { Masimu } \\
\text { m }\end{array}$ & Mean & $\begin{array}{l}\text { Std. } \\
\text { Derration }\end{array}$ \\
\hline Profitabilitas & 36 & .01 & 53 & .1195 & 11594 \\
\hline Eirm_Size & 36 & 20.90 & 32.20 & 28.4648 & 2.66348 \\
\hline Liloxiditas & 36 & 68 & 8.64 & 2,6469 & 1.92550 \\
\hline Struktar_Mods & 36 & .06 & 1.72 & 6957 & 41836 \\
\hline Valid N (fistwise) & 36 & & & & \\
\hline
\end{tabular}
nilai minimum, maximum, mean dan standar deviasi masing-masing variabel.

Tabel 1. Uji Statistik Deskriptif

Sumber: Hasil SPSS

Variabel dependen yaitu Profitabilitas, hasil nilai minimum sebesar 0,01, nilai maximum 0,53, nilai mean 0,1195 dan standart deviation 0,11594 .

Variabel idependen Firm size, hasil dari nilai minimum sebesar 20,90, nilai maximum 32,20, nilai mean 28,4648 dan standart deviation 2,66348.

Variabel independen Likuiditas, hasil dari nilai minimum sebesar 0,68 , nilai maximum 8,64, nilai mean 2.6469 dan standart deviation 1.92550 .

Variabel independen Struktur Modal, hasil dari minimum 0,06, nilai maximum 1.72 , nilai mean 0.6957 dan standart deviation 0,41836 . 


\section{Uji Asumsi Klasik}

Uji asumsi klasik dilakukan beberapa tahap dan beberapa macam. Pengujian tersebut yaitu uji normalitas, uji multikolinieritas,uji autokorelasi, dan uji heteroskedastisitas.

\section{Tabel 2. Uji Normalitas}

\begin{tabular}{|llll|}
\hline & $\begin{array}{c}\text { Unstandardized } \\
\text { Residual }\end{array}$ & Syarat & Kesimpulan \\
\hline & & & \\
Asymp.Sig. & 0,289 & $>0,05$ & Terdistribusi \\
(2-tailed) & & & Normal \\
& & & \\
\hline
\end{tabular}

Sumber: Hasil SPSS

Dari tabel diatas dapat diketahui bahwa nilai signifikansi Kolmogrov Smirnov (K-S) adalah 0,289 , artinya nilai tersebut lebih besar di 0,05 yang berarti bahwa data tersebut terdistribusi normal.

\section{Tabel 3. Uji Multikolinearitas}

\begin{tabular}{|llllllr|}
\hline Variabel & Tolerance & Std & VIF & Std & Keterangan \\
\hline Firm Size & 0,495 & $>0,10$ & 2.022 & $<10$ & Tidak terjadi \\
& & & & & Multikolinieritas \\
Likuiditas & 0,360 & $>0,10$ & 2,774 & $<10$ & Tidak terjadi \\
& & & & & Multikolinieritas \\
Struktur & 0,645 & $>0,10$ & 1,550 & $<10$ & Tidak terjadi \\
Modal & & & & & Multikolinieritas \\
\hline
\end{tabular}

Sumber: Hasil SPSS

Berdasarkan hasil uji multikolinearitas pada tabel diatas dapat diketahui bahwa variabel firm size, likuiditas dan struktur modal memiliki tolerance $>0,1$ dan nilai
VIF $<10$, maka dapat disimpulkan bahwa semua variabel tidak terjadi multikolinearitas.

\section{Tabel 4. Uji Heteroskedastisitas}

\begin{tabular}{lllll}
\hline Variabel & Sig & Syarat & Kesimpulan & \\
\hline Firm Size & 0,371 & $>0,05$ & Tidak & Terjadi \\
& & & Heteroskedastisitas & \\
Likuiditas & 0,062 & $>0,05$ & Tidak & Terjadi \\
& & & Heteroskedastisitas & \\
Struktur & & & Tidak & Terjadi \\
Modal & 0,698 & $>0,05$ & Heteroskedastisitas
\end{tabular}

Sumber: Hasil SPSS

Berdasarkan hasil uji heteroskedastisitas pada tabel diatas menunjukkan bahwa variabel firm size, likuiditas, dan struktur modal memiliki signifikansi > 0,05, maka dapat disimpulkan tidak terjadi heteroskedastisitas.

Tabel 5. Uji Autokorelasi

\begin{tabular}{|lll|}
\hline Run Test & Kriteria & Keterangan \\
\hline 0,063 & $>0,05$ & Tidak Terjadi Autokorelasi \\
& & \\
\hline
\end{tabular}

Sumber: Hasil SPSS

Berdasarkan hasil uji autokorelasi pada tabel diatas menunjukkan bahwa nilai Asymp.Sig2-tailed sebesar 0,063. Jika uji autokorelasi dinyatakn bebas, maka nilai Asymp.Sig2-tailed >0,05. Maka dapat disimpulkan bahwa penelitian ini dinyatakan tidak terjadi uji autokorelasi karena sig lebih 
besar dari standart yaitu (Asymp.Sig2-tailed:0,063>0,05)

Tabel 6. Uji Analisis Regresi Linear Berganda

\begin{tabular}{|l|c|}
\hline \multicolumn{1}{|c|}{ Variabel } & B \\
\hline Constant & 1,184 \\
Firm Size & $-0,307$ \\
Likuiditas & $-0,122$ \\
Struktur Modal & $-0,090$ \\
\hline
\end{tabular}

Sumber: Hasil SPSS

Berdasarkan hasil uji diatas dengan menggunakan bantuan SPSS 20, maka hasil persamaan regresi untuk analisis regresi liniear berganda adalah sebagai berikut:

$\mathrm{Y}_{1}=1,184-0,307 \mathrm{X}_{1}-0,122 \mathrm{X}_{2}-0,090 \mathrm{X}_{3}+\epsilon$

Persamaan regresi liniear berganda yang telah dibentuk di atas mempunyai pengertian.

a) Konstanta yang diperoleh sebesar 1,184 artinya semua variabel independen bernilai 1 persen, maka profitabilitas naik sebesar 1,184.

b) Koefisien regresi variabel Firm Size bernilai -0,307. Artinya variabel Firm Size naik sebesar 1 persen dengan asumsi variabel yang lainnya tetap, maka diikuti penurunan profitabilitas sebesar 0,307.

c) Koefisien regresi variabel likuiditas bernilai $-0,122$, artinya apabila variabel likuiditas naik sebesar 1 persen, maka diikuti penurunan profitabilitas sebesar 0,122 . d) Koefisien regresi variabel struktur modal bernilai -0,090, artinya apabila variabel struktur modal naik sebesar 1 persen, maka diikuti penurunan profitabilitas sebesar 0,090.

Tabel 7. Uji Kelayakan Model

\begin{tabular}{|llllll|}
\hline \multicolumn{7}{|c|}{ Uji Kelayalas Model $(\mathrm{Cji})$} \\
\hline Hipotesis & Fhituat & F table & Sig & Srarat & Keputusan \\
\hline Ha & 3,073 & 2,901 & 0,042 & $<0,05$ & Model Lasak \\
\hline
\end{tabular}

Sumber: Hasil SPSS

Berdasarkan tabel diatas diperoleh $\mathrm{F}$ hitung sebesar 3,073 > F tabel 2,901 dan signifikansi sebesar $0,042<0,05$ sehingga nilai signifikansi lebih kecil dari 0,05. Hal ini menunjukan bahwa variabel independen signifikansi secara bersama-sama berpengaruh terhadap variabel dependen.

Tabel 8. Uji Hipotesis (uji t)

\begin{tabular}{|llllll|}
\hline \multicolumn{7}{|c|}{ Uji Hipotesis (uji t) } \\
\hline Hipoteris & T Hitumg & I thbel & Sig & Syagat & Resimpalan \\
\hline $\mathrm{H}_{1}$ & $-1,767$ & $-2,037$ & 0,08 & $\infty 0,05$ & Ditolak \\
$\mathrm{H}_{2}$ & $-2,226$ & $-2,037$ & 0,03 & $\infty 0,05$ & Diterima \\
$\mathrm{H}_{3}$ & -2785 & $-2,037$ & 0,00 & $\infty 0,05$ & Diterima \\
\hline
\end{tabular}

Sumber: Hasil SPSS

Berdasarkan tabel diatas maka uji hipotesis (Uji t) sebagai berikut:

$\begin{aligned} \mathbf{H}_{1} \text { : } & \text { Firm Size berpengaruh } \\ & \text { terhadap profitabilitas } \\ & \text { Berdasarkan hasil pengujian } \\ & \text { uji } \mathrm{t} \text { diperoleh } \mathrm{t} \text { hitung untuk } \\ & \text { variabel firm size sebesar - } \\ & 1,767 \text { yang artinya t hitung < } \mathrm{t} \\ & \text { tabel }(-1,767<-2,037) \text { dan } \\ & \text { nilai signifikansi sebesar } 0,8\end{aligned}$


yang artinya nilai signifikansi $>0,05(0,87>0,05)$ maka disimpulkan bahwa firm size tidak berpengaruh signifikan terhadap profitabilitas. Sehingga $\mathrm{H}_{0}$ diterima dan $\mathrm{H}_{1}$ ditolak.

\section{$\mathbf{H}_{2}$ : Pengaruh} berpengaruh profitabilitas

Berdasarkan hasil uji $t$ diperoleh profitabilitas untuk variabel likuiditas sebesar 2,226 yang artinya $t$ hitung $>t$ tabel $(-2,226>2,037)$ dan nilai signifikansi sebesar 0,03 yang artinya nilai signifikansi > $0,05(0,33<0,05)$ maka dapat disimpulkan bahwa likuiditas berpengaruh signifikan terhadap profitabilitas.

Sehingga disimpulkan bahwa $\mathrm{H}_{0}$ ditolak dan $\mathrm{H}_{2}$ diterima

\section{$\mathrm{H}_{3}$ : Pengaruh Struktur Modal berpengaruh terhadap profitabilitas}

Berdasarkan uji $\mathrm{t}$ diperoleh $\mathrm{t}$ hitung untuk variabel struktur modal sebesar -2,785 yang artinya $\mathrm{t}$ hitung $>\mathrm{t}$ tabel ($2,785>-2,037)$ dan nilai signifikansi sebesar 0,00 yang artinya nilai signifikansi < $0,05(0,00<0,05)$ maka dapat disimpulkan bahwa struktur modal berpengaruh signifikan terhadap profitabilitas.

Hasil dari penelitian ini menunjukan bahwa struktur modal berpengaruh signifikan terhadap profitabilitas sehingga $\mathrm{H}_{0}$ ditolak dan $\mathrm{H}_{3}$ diterima.

Tabel 9. Uji Koefisien Determinasi

\begin{tabular}{|c|c|}
\hline \multicolumn{2}{|c|}{ Hasil Uji Koefisien Determinasi } \\
\hline Adjusted R Square & Kesimpulan \\
\hline 0.151 & $\begin{array}{l}\text { Berpengarah } \\
\text { sebesar } 15,1 \%\end{array}$ \\
\hline
\end{tabular}

Sumber: Hasil SPSS

Diperoleh nilai adjusted $R^{2}$ $15,1 \%$ sehingga dapat disimpulkan bahwa variabel Firm Size (X1), Likuiditas (X2) dan Struktur Modal (X3) mempengaruhi Profitabilitas (Y) sebesar $15,1 \%$ dan $84,9 \%$ dipengaruhi oleh faktor lain yang tidak diteliti dalam penelitian ini.

\section{KESIMPULAN}

1. Berdasarkan hasil penelitian yang telah dilakukan bahwa firm size tidak berpengaruh terhadap profitabilitas._Diperoleh t hitung untuk variabel firm size sebesar $-1,767$ yang artinya $t$ hitung $<\mathrm{t}$ tabel $(-1,767<-2,037)$ dan nilai signifikansi sebesar 0,08 yang artinya nilai signifikansi $>0,05$ $(0,08>0,05)$ maka disimpulkan bahwa firm size tidak berpengaruh signifikan terhadap profitabilitas.

2. Berdasarkan hasil penelitian yang telah dilakukan ditemukan bahwa likuiditas berpengaruh terhadap profitabilitas. Hasil uji t 
diperoleh profitabilitas untuk variabel likuiditas sebesar -2,226 yang artinya $t$ hitung $>t$ tabel ($2,226>2,037)$ dan nilai signifikansi sebesar 0,03 yang artinya nilai signifikansi $>0,05$ $(0,33<0,05)$ maka dapat disimpulkan bahwa likuiditas berpengaruh signifikan terhadap profitabilitas.

3. Berdasarkan penelitian yang sudah dilakukan ditemukan bahwa struktur modal berpengaruh terhadap profitabilitas. Dapat dilihat dari pada tabel uji t diperoleh $t$ hitung untuk variabel struktur modal sebesar $-2,785$ yang artinya $t$ hitung $>\mathrm{t}$ tabel $(-2,785>-2,037)$ dan nilai signifikansi sebesar 0,00 yang artinya nilai signifikansi $<0,05(0,00<0,05)$ maka dapat disimpulkan bahwa struktur modal berpengaruh signifikan terhadap profitabilitas. Hasil dari penelitian ini menunjukan bahwa struktur modal berpengaruh signifikan terhadap profitabilitas.

\section{SARAN}

Berdasarkan kesimpulan dan keterbatasan dalam penelitian ini, maka dapat disampaikan beberapa saran sebagai berikut :

a. Agar dapat diteruskan pada perusahaan lain sehingga tidak hanya perusahaan sektor makanan dan minuman dan masa periode yang lebih lama agar memperkuat hasil penelitian.

b. Bagi peneliti selanjutnya diharapkan dapat menambah variabel yang lain agar dapat memperkuat hasil penelitian.

\section{DAFTAR PUSTAKA}

Abeyrathna, S., \& Priyadarshana, A. (2019). Impact of Firm size on Profitability. International Journal of Scientific and Research Publications, Volume 9, No. 6 (2019) hal 561-564,

https://www.researchgate.net/p ublication/334187935_Impact of_Firm_size_on_Profitability

Astivasari, N., \& Siswanto, E. (2018). Pengaruh Struktur Modal dan Ukuran Perusahaan Terhadap Profitabilitas Perusahaan Indonesia (Studi Pada Perusahaan Sektor Properti dan Real Estate yang Listing di BEI Periode 20122014). Jurnal Ekonomi Bisnis, volume 23, No. 1 Mei 2018, Hal 35-42, http://journal2.um.ac.id/index.p hp/ekobis/article/view/10240/4 772

Brealey, Myers, R, A, Marcus, \& A.J. (2011). Dasar-Dasar Manjemen Keuangan Perusahaan , 5. 2 (alih bahas: Bob Sabran). Prosiding Seminar Nasional Akuntansi Vol 2, No. 1 (2019), http://openjournal.unpam.ac.id/ index.php/SNU/article/view/26 53/2090

Chamler, R., Musah, A., \& Gakpetor, E. D. (2018). The Impact of Liquidity on Performance of 
Commercial Banks in Ghana. Academic. Journal of Economic Studies, Vol 4, No. 4, 2018, hal 78-90, https://econpapers.repec.org/art icle/khescajes/v_3a4_3ay_3a20 18_3ai_3a4_3ap_3a78-90.htm

Parvin, S., Chowdhury, A. M., shiddiqah, A., \& Ferdous, J. (2019). Effect of Liquidity and Bank Size on the Profitability of Commercial Banks in Bangladesh. Asian Business Consortium, 2019, Vol 9, No.1, Hal 7-10, https://econpapers.repec.org/art icle/risasbure/0001.htm

Santini, N. K., \& Baskara, I. K. (2018). Pengaruh Perputaran Modal Kerja, Ukuran Perusahaan. E-Jurnal Manajemen Unud, 2018, Vol. 7, No. 12, Hal 6502-6531, https://ojs.unud.ac.id/index.php /Manajemen/article/view/4145 $8 / 26865$

Sukmayanti, N. P., \& Triaryati, N. (2019). Pengaruh Struktur Modal, Likuiditas dan Ukuran. E-Jurnal Manajemen, Vol. 8, No.1, 2019, Hal 7132-7162, https://ojs.unud.ac.id/index.php /Manajemen/article/view/4152 $8 / 27411$

Wibowo, A., \& Wartini, S. (2012). Efisiensi Modal Kerja, Likuiditas Dan Leverage Terhadap Profitabilitas . Jurnal Dinamika Manajemen, Vol. 3 No. 1 2012, Hal 49-58. https://journal.unnes.ac.id/nju/i ndex.php/jdm/article/view/245 $9 / 2512$

Wulandari. (2017). Pengaruh Likuiditas dan Struktur Modal Terhadap Profitabilitas.
Nasional, JOM FISIP. Vol. 4 No. 2 Oktober 2017, Hal 1-12, https://media.neliti.com/media/ publications/184837-IDnone.pdf 